\title{
Report on the First International Congress on Systemic Medicine, Gas Discharge Visualization (GDV) and Electro-oncotherapy (ECT)
}

\author{
José A. Olalde Rangel and Oswaldo del Castillo
}

Adaptogenic Educational Medical Centers (AEMC), Caracas, Venezuela

This event, held in Caracas, Venezuela on the $21^{\mathrm{ST}}$ and $22^{\mathrm{ND}}$ January at the Tamanaco Intercontinental Hotel, was attended by close to 1000 medical doctors (MDs) and students. It was the largest evidence-based complementary and alternative medicine (ECAM) meeting ever held in this country and constituted a landmark. Those attending were orthodox physicians in search of new alternatives. Massive media coverage by 40 local press agencies, newspapers, television networks and radio stations ensured that the entire country resonated with the event, recognizing the influence of this medical practice in Venezuela, its potential for the remission of chronic degenerative illnesses and its international relevance. It is significant that this first congress on systemic medicine (SM), gas visualization discharge (GDV) and electro-oncotherapy (ECT) counted on crucial local support for unparalleled logistics. This enthusiastic participation strongly supported the view that $\mathrm{SM}$ is a way to decrease the high costs of treating chronic degenerative diseases. SM is a consolidated tendency-in Venezuela-with a network of 33 medical units and $>150$ trained MDs. They are working systematically with adaptogenic herbs in what constitutes the third largest medical network in the country, surpassed only by the government's ambulatory system and the Red Cross Association. SM postulates that the common denominator of 'unrelated' sickness is an entropy increase, which manifests itself by a reduction of synergic bonds in key elements of the human organism (1). This chaos increase affects the system's internal energy, biological intelligence and organization, which constitute the system's three vital elements, i.e. the essential parameters of life. Therefore, according to SM, the solution to sickness lies in a reduction of entropy via the enhancement of these three mutually synergic variables. This was perceived among attendees as

For reprints and all correspondence: José A. Olalde Rangel, Adaptogenic Educational Medical Centers (AEMC), Caracas, Venezuela. Tel: +58-2129459925; Fax: +58-212-9435911; E-mail: adaptogen@ cantv.net one of the most important conclusions derived from lectures and presentation of 17 clinical studies by scientists and medical doctors in the 'First International Congress on Systemic Medicine, GDV and ECT'.

\section{Systemic Medicine at the Threshold of ECAM}

Introduction to the event and welcome was provided by Eng. Jose Olalde, Founder and President of Systemic Medicine Centers, who offered a comprehensive presentation of the systemic theory entitled: An Introduction to Systemic Medicine (1). The foundation of the theory, the common denominator in all living systems, the thermodynamic validation and the preview of clinical results provided some of the presentation's milestones. The numerous lectures by internationally reputed scientists were jump-started by Professor Edwin Cooper PhD, ScD, David Geffen School of Medicine, UCLA and Founding Editor in Chief of the international peer-reviewed journal $e C A M$. This is an open access journal published by Oxford University Press. Professor Cooper emphasized the need for non-anecdotal relevance of ECAM in a lecture entitled: 'Evidence Based Complementary and Alternative Medicine: From Natural Products to CAM to ECAM'. Also, Professor Cooper made interesting references to the benefits of modern biomedical prospecting (2). The use of adaptogens and their significance in SM was presented in 'Adaptogens and Their Medicinal Action in the Light of the Systemic Theory' by Dr Anatoly Antóshechkin, PhD, Member of the Russian Federation Medical Sciences Academy (3). Dr Meyer Magarici, Medical Director and Founding Member of the Venezuelan Society of Systemic Medicine lectured on the phytopharmacology of adaptogens as models in the elaboration of a systemic protocol. The presentation was entitled: 'Action Mechanisms of a Systemic Medicine Protocol'. Dr Konstantin Korotkov, PhD and Professor at St Petersburg State University, Russian Federation, captured the audience's

(C) The Author (2005). Published by Oxford University Press. All rights reserved.

The online version of this article has been published under an open access model. Users are entitled to use, reproduce, disseminate, or display the open access version of this article for non-commercial purposes provided that: the original authorship is properly and fully attributed; the Journal and Oxford University Press are attributed as the original place of publication with the correct citation details given; if an article is subsequently reproduced or disseminated not in its entirety but only in part or as a derivative work this must be clearly indicated. For commercial re-use, please contact journals.permissions@oupjournals.org 
interest with: 'Scientific Analysis of the Human Energy Field using Gas Discharge Visualization (GDV)'. This presentation focused on the modeling of the human energy field using the GDV method made possible thanks to a technological application of quantum physics (4). Dr Len Wisneski PhD, Professor of Medicine at George Washington University Medical Center expanded on the use of GDV with a talk entitled: 'Experience on Human Energy Field Applications in Medicine'.

\section{Presentations of Clinical Studies}

Seventeen clinical studies were presented on 12 chronic degenerative diseases. Overall results were an outstanding $>80 \%$ success rate, which reveals an important breakthrough in modeling a novel systematic phytomedical protocol to treat chronic degenerative illnesses by providing negative entropy. The presentations included, among others, an abridged version of the protocol per pathology, phytopharmacology of adaptogen use, results obtained and testimonials. All these clinical studies as well as the lectures were published in the Congress proceedings and made available in a book as well as CD format to all congress attendees (5). The pathologies presented by leading Venezuelan physicians which work at the systemic clinics all over the country were the following. (i) Genitourinary disorders, i.e. chronic renal failure and benign prostate hyperplasia; (ii) peripheral and vascular disorders, i.e. varicose ulcers; (iii) neurological disorders, i.e. multiple sclerosis and Parkinson's disease; (iv) osteoarticular disorders, i.e. arthritis; (v) metabolic disorders, i.e. diabetes; diabetic disorders, diabetic neuropathy and diabetic foot; (vi) skin disorders, i.e. psoriasis; (vii) cancer, i.e breast and prostate; and (viii) hepatic disorders, i.e. chronic hepatopathy

\section{Ancillary Presentations}

A particular note should be made concerning the presentation of ECT. This is a new and powerful tool against cancer. ECT, also called electrotherapy, consists of inducing electrolysis in malignant cells. ECT presently is practiced in $>1000$ Chinese hospitals with an average clinical success that exceeds $80 \%$ in solid malignant tumors and hemangiomas. It is surprising that such a powerful technique has not yet received FDA approval for use in the USA despite the existence of $>100$ scientific clinical studies concerning its performance indexed in Medline. Dr José Guiada Director of ECT at the Systemic Clinics lectured on the principles behind this technique, its application and results that make this technique a powerfulally in the treatment of cancer. There were also important lectures on the new quantum physics-based GDV method developed by the Dr Konstantin Korotkov. The experience at the Systemic Clinics with GDV demonstrated its capacity to measure quantum changes parallel to the body's clinical changes in those pathologies where the patient had a below normal level of energy, after being treated with SM. The study presented by Dr Libya Gomes, Surgeon, Systemic specialist MD, and co-authored by Eng. Jose Olalde was entitled: 'GDV Energy
Measurements in Evolution of Patients'. Dr Gomes demonstrated the utility of this technology in detecting low energy levels in patients with different pathologies and how the systemic treatment went hand in hand with an improvement in symptoms and increase of energy levels. Dr Konstantin Korotkov and Dr Len Wisneski demonstrated GDV and the medical application of the human energy field. Mr Hakan Johanson, President of Nulab Laboratories, Inc., presented the importance and significance of quality control in phytoceuticals entitled 'Quality Controls in the Manufacturing of Natural Products'. Dr Alex Vainshelboin, PhD, Research Director, AVEDA Corporation, lectured on 'Intrinsic Energy of Odorant and Olfactory Response Using the Human Energy Field'. Also to be noted were: (i) 'Ecosonographic Confirmation of Systemic Medicine's Results' by Dr Pedro Vega, MD, Surgeon, Ecosonography specialist; (ii) 'The Common Denominator to Sickness, Thermodynamic Fundaments, Statistical Correlation' by Eng. José Olalde, Systemics Founder; and (iii) 'Hospital Study of the Effects of Adaptogens in Arthritis' by Dr Rosa Briceño, MD, Service Chief of the National Rehabilitation Institute, Perez Carreño Hospital, Caracas, Venezuela.

\section{Conclusion and Significance}

SM postulates: (i) most chronic degenerative sickness that evolves in the second stage of life is caused by an endogenous entropy increase in the body; (ii) an entropy increase is the common denominator in all such sickness, i.e. all sickness has this in common; (iii) the treatment of age-related disease should encompass the administration of negative entropy to the organism; (iv) all negative life impacts that cause disease in the earlier stages of life also provide harmful positive entropy; this is the cause of chemical, biological, physical or emotional stress; (v) the common denominator to all disease is an excessive entropy increase; (vi) the treatment of sickness should consider the reduction of entropy in the system; and (vii) an ideal medicine, whether natural or synthetic, is that which can provide negative entropy to a living system. If entropy increase is the cause of disease, then how do we reduce it? The answer is by utilizing any and all substances that can increase energy, biological intelligence and organization in the living system.

\section{References}

1. Olalde JA. The systemic theory of living systems and relevance to CAM. eCAM 2005;2:13-18.

2. Cooper EL. Bioprospecting: a CAM frontier. eCAM 2005;2:1-3.

3. Kormosh N, Laktionov K, Antoshechkina M. Effects of an advanced adaptogenic formula on cell and humoral immunity in patients with advanced ovary cancer. N.N. Blokhin Cancer Investigation Center, Russian Academy of Medical Sciences, Moscow, Russia. December 2004. In press.

4. Korotkov K. Light after Life. Backbone Publishing Co., Fairlawn, NJ, 1998.

5. Proceedings of the First International Scientific Congress of Systemic Medicine, GDV and Electro-Oncotherapy. January 2005, Caracas.

Received 24 February, 2005; accepted March 21, 2005 


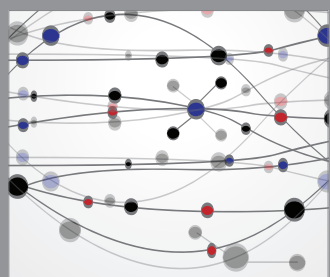

The Scientific World Journal
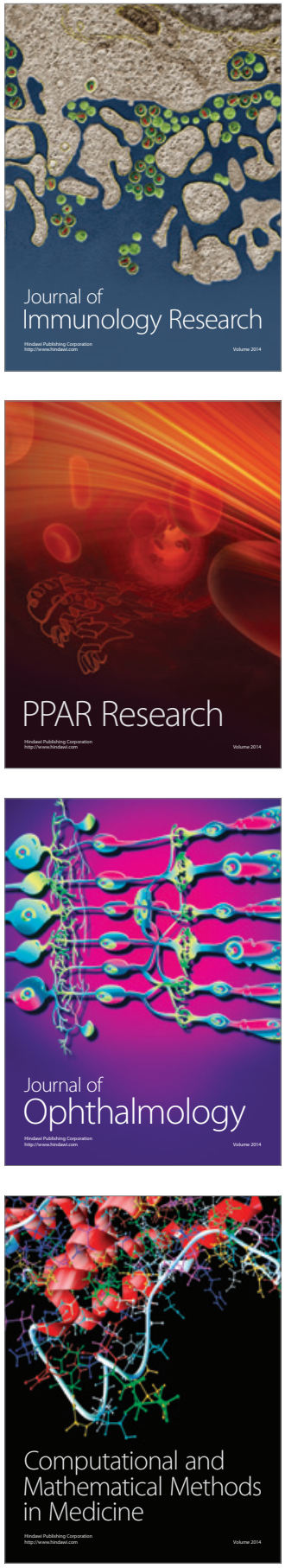

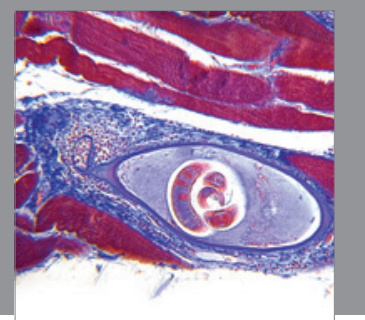

Gastroenterology

Research and Practice
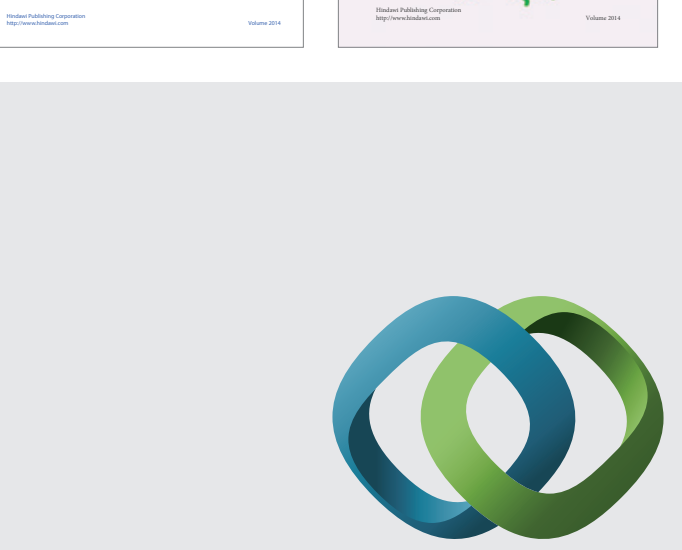

\section{Hindawi}

Submit your manuscripts at

http://www.hindawi.com
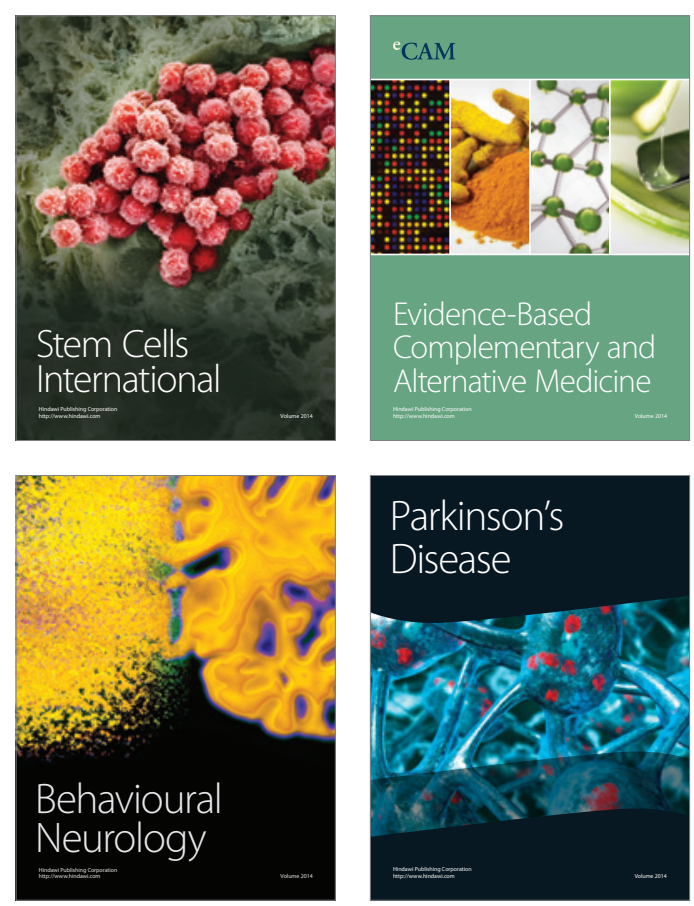

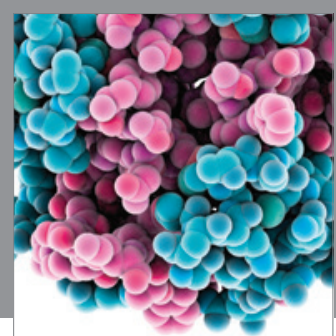

Journal of
Diabetes Research

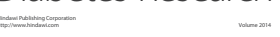

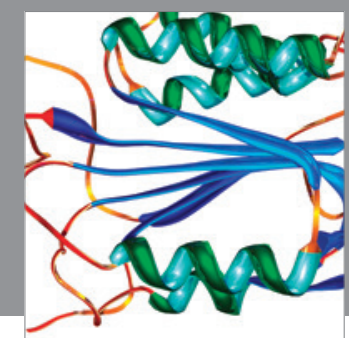

Disease Markers
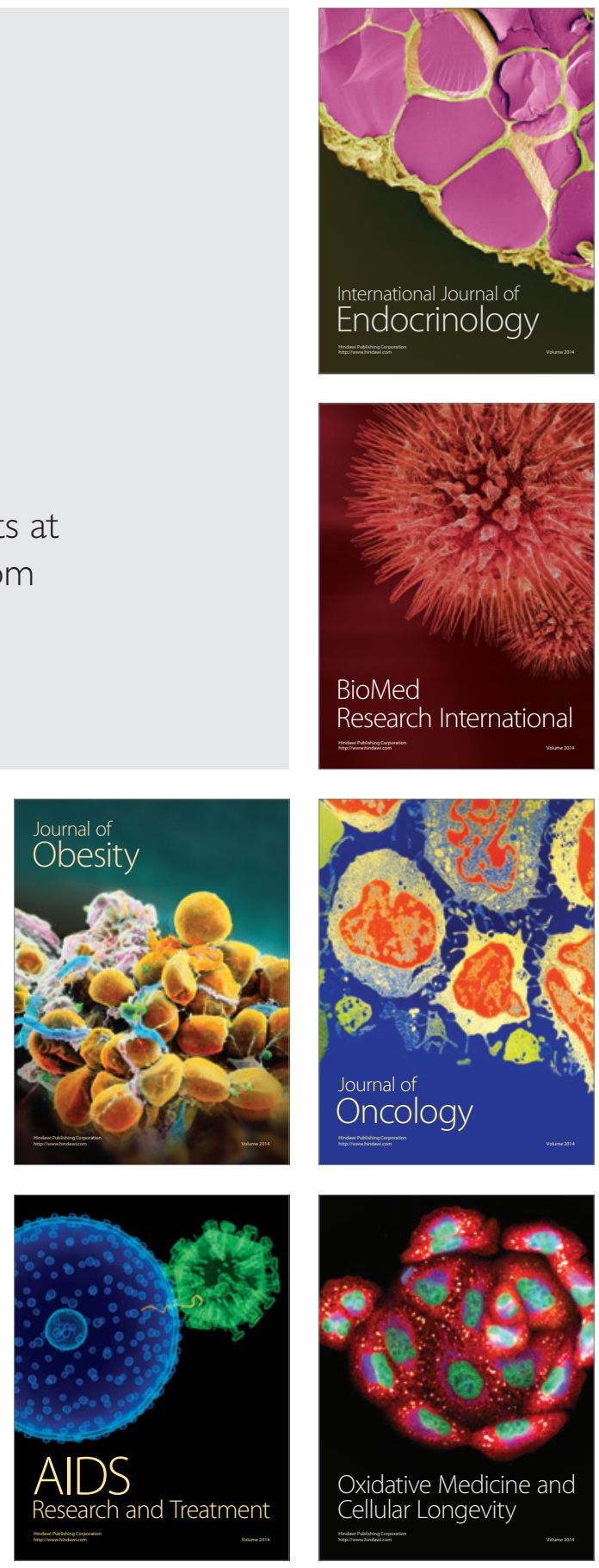